\title{
Paste backfill — adding value to underground mining
}

\author{
N.M. Slade Golder Paste Technology (Europe) Ltd, United Kingdom
}

\begin{abstract}
The application of paste as backfill in underground mines has been demonstrated in a variety of mining operations to create advantages in delivering improved production rates and reduced operating costs, providing an opportunity to add value to the business. This can deliver short term gains to an operation as well as enable longer term strategic goals to be enhanced. An underground mine normally uses backfill to assist in maximising the recovery of the ore in the mine, as the value of the material processed, refined and sold offsets the cost of the backfill placed. In addition this also allows the mine to recover more of the Mineral Resource, creating an opportunity to increase the Ore Reserve. Historically backfill has tended to be sand and cement placed as a slurry into the mine stope. This is often referred to as cemented hydraulic fill. Variants to this are also used including the placement of additional aggregate and/or rock into the stope with the cemented sand slurry. This paper describes the differing range of backfill materials used in underground mines and highlights the merits of paste backfill from various perspectives of value, cost, operations and ore production scheduling. The paper goes on to describe a case study of the use of two differing backfill materials and describes the financial, mine design, ore reserve and scheduling attributes that deliver additional value to a given underground mining operation.
\end{abstract}

\section{Introduction}

The application of paste as backfill in underground mines has been demonstrated in a variety of mining operations to create advantages in delivering improved production rates and reduced operating costs, providing an opportunity to add value to a business.

An underground mine normally uses backfill to assist in maximising the recovery of the ore in the mine, as the value of the material processed, refined and sold offsets the cost of the backfill placed. This allows the mine to recover more of the Mineral Resource and in so doing so creates the opportunity to increase the Ore Reserve and potential to deliver longer length of operations (extend mine life).

\section{Types of backfill}

Historically backfill has tended to be sand and cement placed as a slurry into the mined stope. This is often referred to as cemented hydraulic fill (CHF). This method is used in many operations today. Variants on this are also used including the placement of aggregate or rock into the stope with the cemented fill, such as those described by Bloss et al. (1993). The application of paste backfill is used in many operations and is in many cases the preferred choice of backfill to use in an underground mine for a variety of reasons addressed in this paper.

Backfill source materials are largely made up from the tailings waste generated a mining operations mineral processing activities. Whereas hydraulic fill uses coarse sands from cyclone underflow, paste generally includes the full mill tailings, though variations on this do exist. While this differentiates the two fills from a perspective of particle gradation, the major aspect were the performance differs is that paste has a reduction of excess water usage, modified pipeline rheology (or pipeline flow), greater consistency as an engineered backfill and the ability to be placed in the stope at a faster delivery rate thereby generating significant productivity opportunities in the underground mine. 


\subsection{Paste}

Although from a technical perspective the material descriptions stated previously are inaccurate, the vision they conjure up is correct. A more technically correct appreciation of paste is commonly said to include the following characteristics:

- non-segregating mixture of solids and water

- exhibiting minimal water bleed when left idle

- meaningful slump measures no more than $253 \mathrm{~mm}$

- with no critical flow velocity

- percent solids dependent on particle size distribution (PSD) and other factors.

\subsection{Cemented hydraulic fill}

Rather than go on at any length to provide a technical description of CHF backfill characteristics, it is intuitively obvious that they are different to those above. Figure 1 shows what the slump looks like for the differing natures of material and as this is the most simple and common test for evaluation it is worthy of note.

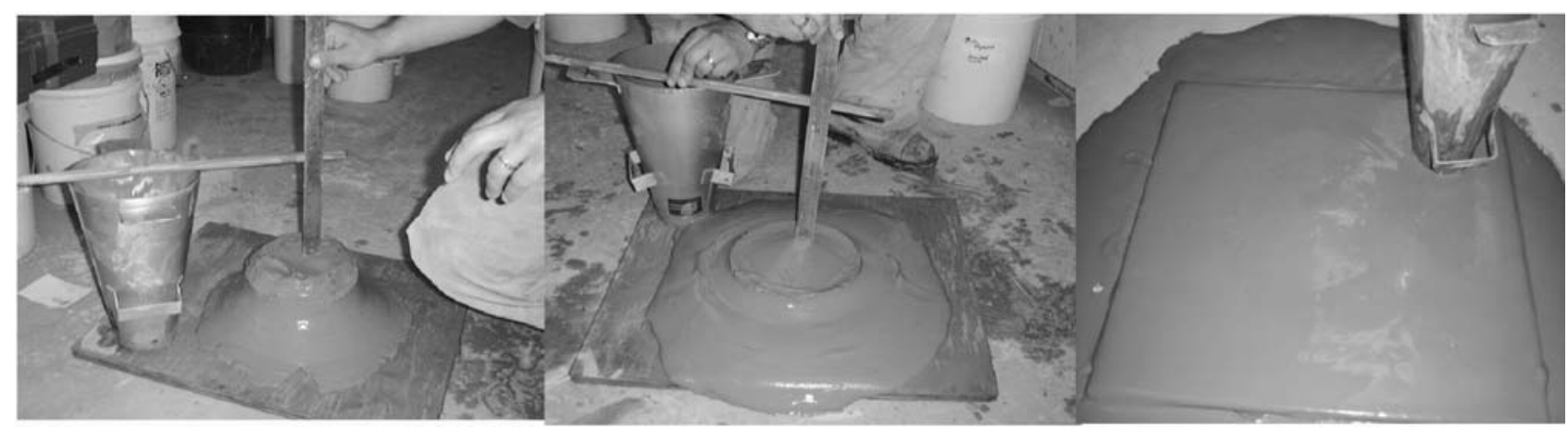

$$
\text { Paste - } 177 \mathrm{~mm} \text { slump } \quad \text { Paste }-253 \mathrm{~mm} \text { slump Slurry - no slump }
$$

\section{Figure 1 Generic examples of the slump cone test for differing backfill mix designs}

\section{$3 \quad$ Paste backfill benefits}

The use of paste backfill provides a number of benefits over conventional CHF. These are described as both direct and indirect benefits.

\subsection{Direct benefits}

Direct benefits achieved through the use of paste backfill in underground mining include:

- increased disposal of tailings waste into underground (reducing surface footprint)

- reduced number of pipe reticulation changes underground (no need to place into multiple stopes to manage drainage)

- reduced risk of line change error (resulting in the accidental placement of fill in the incorrect stope)

- reduced amount of backfill associated water and flushing water

- reduced labour requirements (less reticulation line changes required, less water controls and management)

- increased utilisation of backfill plant and the pipe reticulation systems

- lower cost and more efficient bulkheads (less materials required) 
- reduced requirements for concrete bulkheads on higher sub-levels (potential to use rock and shotcrete barricades)

- reduction in the time to fill the stope (CHF has to stop to allow drainage)

- reduced cement content

- reduction in the curing time

- lower levels of wear/abrasion on pipe reticulation systems.

\subsection{Indirect benefits}

Indirect benefits achieved through the use of paste backfilling underground mining include:

- decrease in the amount of time between neighbouring stopes in the production schedule

- reduced maintenance on vehicle fleet (less water is placed into the mine or drains from the stope filling areas, resulting in reduced water for vehicles and people to work in or travel through)

- less time a stope is remaining unfilled after production, reducing the likelihood for overbreak to occur which can affect recovery of ore in the neighbouring stopes

- reduction in potential rock mass deformation in to the stope - improving local and regional ground behaviour

- improved mine environment (reduced casual water, reduced high alkalinity water, reduced humidity)

- reduced hazard potential to the workforce through the elimination of large pools of alkaline backfill water

- lower likelihood of waste rock and fill dilution as paste is more homogenously placed (less contamination in the mill processing).

These direct and indirect items all impact on stope cycle time and mine efficiencies. This equates to the business value and performance of an operation.

Although many of the benefits create a relatively small cost reduction to the overall operating cost, a reduction of up to $10 \%$ in the overall mining unit cost is achievable in larger scale stoping operations.

\section{$4 \quad$ Paste backfill challenges}

The use of paste backfill of course has some challenges to underground mining operations that must also be considered in relation to conventional cemented hydraulic fill. These include:

- increased capital cost of plant infrastructure

- increased operating pressure for the underground reticulation system

- reduced horizontal distance by which the backfill can be gravity placed.

Although the list is less in number than for the benefits, these are important considerations for the design of the system and can sometimes be constraints on a smaller scale of mining operation to use paste backfill.

\section{$5 \quad$ Value}

\subsection{Shareholder value}

If the business driver or goal is to maximise shareholder value, the most widely used representation of this being net present value (NPV), refer to Runge (1998) for a full discussion, then it is appropriate to consider this during evaluations of all key potential expenditures to ensure value based business decisions are made. 


\subsection{Net present value}

Intuitively, if you have a scenario where the NPV is increased for a project, even with increased capital expenditure, basic theory suggests the project will make a financial return and the project should go ahead. In practice there are limitations to this theoretical outcome such as available capital within the business or indeed the capital finance market place as has been witnessed in 2009 or the risk associated with the mining project. In such cases, the financial imperative for a project may not just be a positive NPV, but it may also be the return on the investment, the payback period or the inherent risk involved in the project as compared to other projects the business is assessing.

\subsection{Financial analysis}

Given that discounted cash flow and NPV is the most commonly used indicator of a project's financial strength, a thorough financial examination of backfill options linked with mining methods for orebody extraction should be undertaken. This is important as the lowest capital cost option may not be the most value adding option to the project or mining operation. The merits of analysing a project over its lifecycle can be said to be a more strategic assessment than that purely focused on operating cost or technical simplicity.

A financially favourable alternative to cemented hydraulic backfill is to engineer the material to a paste. This is the focus of this paper and is discussed to illustrate how paste backfill can add value to projects.

Influences on the decisions mining companies make with regard to managing capital expenditure on aspects such as backfill are driven by the business characteristics and culture of the company. More specifically how its business goals relate to the short or longer term value of the company, what approach it chooses to take to manage financial risk and cash flow status.

Often capital cost constraints can limit the resources available to develop or improve an operation. As a consequence, it is not uncommon that management of backfilling is often undertaken as CHF. This is a simpler and more conventional option but does not necessarily afford the best value for the business.

\section{Adding value}

The biggest opportunity presented by the application of paste fill is in the increased production rates achievable in the mine, as a result of quicker filling and curing. Curing time maybe reduced by up to $70 \%$ and filling rates may be increased by 25 to $100 \%$ depending on stope characteristics. In a variety of situations the cost of the backfill is also reduced, as a backfill with less water in its matrix, requires less cement to achieve the same strength characteristics.

The ability to increase production rates and reduce stope cycle schedule times has the potential to add the significant value to an operation. This is simply driven by mining more metal at a quicker rate which allows greater revenue to be made in a shorter period of time than would otherwise occur. If this additional revenue to the business is greater than the additional cost for a given time period then the NPV is increased.

A number of options are available in an underground mine to achieve this:

- increase of stope ore mined over what would otherwise occur in a backfill schedule constrained mine

- increase overall mine throughput by reducing the 'bottle neck' of backfill schedule or access constraints

- potential to increase head grade of throughput by having more stope production choices in a schedule for a given amount of ore throughput (assuming shaft, decline or mill capacity is constrained).

In other situations the use of a paste backfill in combination with changes to a mining method in an underground mine can also provide opportunities to a business that may not have been achieved by the use of a paste backfill alone, such as that described by Li et al. (2002).

The significance of designing, planning and scheduling the backfill system requirements for an underground mine with as much focus as the ore production requirements cannot be under estimated in achieving its 
strategic plan for the underground mine. Many cases exist where backfilling has not had the same focus to be placed in the empty stopes as the production of ore from them. In such scenarios schedule flexibility is reduced, grade flexibility and opportunities to optimise the mining plan are constrained. This can result in the medium term production plans and ore reserves being put at risk. Slade et al. (2006) describes aspects of this topic related to a case example in a discussion of strategic and tactical approaches to mining.

\subsection{Surface waste disposal}

Although the focus of this paper is on underground backfilling with paste, examining a mining operation holistically also warrants mention of the surface disposal of tailings, by placing paste as backfill, a reduction in the volume of tailings material to be disposed of on the surface of an operation is achieved. Subject to any particular case, this is likely to afford some gains for the operation and indeed if tails is disposed of as a paste may well yield significant gains for the mining business in the following aspects as summarised by Slade et al. (2009):

- smaller tailings disposal footprint (up to $40 \%$ ) with a steeper beach angle (up to $5^{\circ}$ )

- smaller dam engineering

- lower water consumption

- negligible bleed water release

- no critical velocity required to avoid settling in transportation to discharge

- reduced closure cost (10 to $75 \%$ depending on the characteristics of the waste)

- reduced operating risk liability

- reduction in contamination/leachate potential

- potential to not require impervious liner and monitoring systems.

\section{$7 \quad$ Case example}

\subsection{Introduction}

The benefits achieved from the indirect and direct factors in an underground mine will vary dependant on a case by case scenario for any given mining operation. In the majority of scenarios, if a metal production rate increase can be achieved, this will provide the greatest gain to the business.

Where multiple stopes are being mined in one or more orebodies, the mine production schedule is constrained by the time taken to fill and cure any stope, the greatest gain can be delivered through the use of paste backfill. This is an example discussed in this paper.

\subsection{Background}

In this example, an orebody has eight stopes to mine that require backfilling to maximise ore recovery. Each stope is 35,000 tonnes. A plan view of the orebody, stopes and drives is schematically shown in Figure 2. This is called a retreating stope sequence, extracting the stopes one at a time from 1 through to 8.
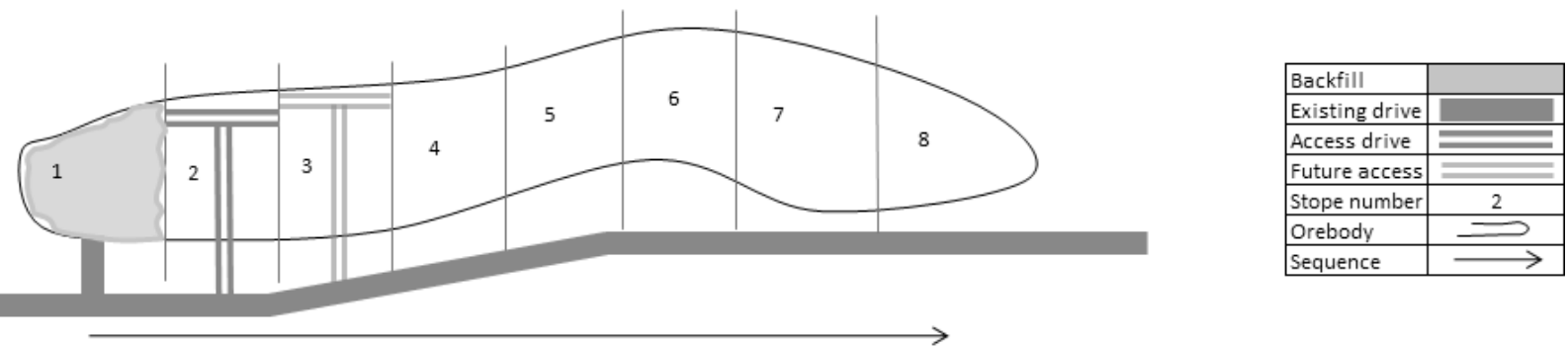

Figure 2 Plan view of orebody with eight stopes to be mined and backfilled in a retreating sequence 
In this case of a simple sequence Stope 1 is extracted first, filled and then Stope 2. This sequence is followed retreating to the right finishing with Stope 8. The time taken to extract the whole area is a function of the major tasks required in the mining area. This includes development mining, production drilling, blasting, and production mucking and filling. Figure 3 represents the major tasks of the stopes lifecycle with backfilling in sequential order - not specific timelines for each task.

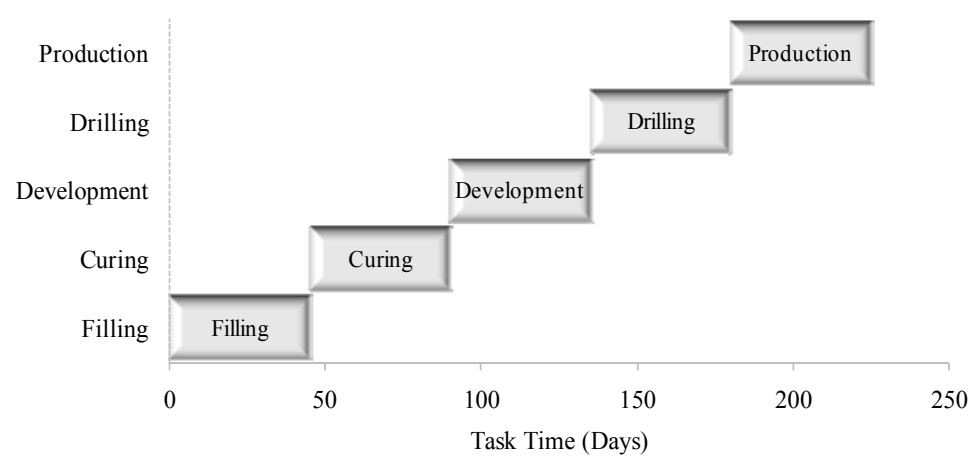

Figure 3 Major tasks and sequential timeline schedule (left to right) of stope lifecycle

\subsection{Stope cycle time and ore scheduling}

Examining cases of CHF stope cycle time versus paste filling cycle time there are four areas of time based improvement with paste. These are:

- reduced filling time, as paste placement does not require stoppages to allow excess water drainage to occur from within the stope

- reduced curing time of the fill mass before exposure with the neighbouring stope. In different case studies it is apparent that curing times for paste are generally at one month or less, whereas cemented hydraulic fill curing times vary from one month to three months. This is dependent on local site factors, scale of filled stope, engineering requirements and risk management

- reduced production mucking time as dilution is reduced (the paste backfill is more homogenous) and so the volume of material handled is reduced

- increased metal production rate as a function of recovery in the mineral processing facility, because of reduced fill dilution.

Base data for this example of the schedule related aspects of the mining cycle is presented in Table 1. 
Table 1 Stope physicals and scheduling data summary

\begin{tabular}{|c|c|c|}
\hline Stope Cycle Element & With CHF Backfill & With Paste Backfill \\
\hline Stope ore tonnage & 35,000 & 35,000 \\
\hline Stope volume $\left(\mathrm{m}^{3}\right)$ & 12,000 & 12,000 \\
\hline Drawpoints & 1 & 1 \\
\hline Plan area $(\mathrm{m})$ & $17 \times 25$ & $17 \times 25$ \\
\hline $24 \mathrm{hr}$ fill rate $(\mathrm{t} / 24 \mathrm{hrs}) *$ & 500 & 1,000 \\
\hline Stope curing time (days) & 90 & 30 \\
\hline Sublevels no. (15 m intervals) & 3 & 3 \\
\hline Height overall (m) & 30 & 30 \\
\hline Development required (m) & 181 & 181 \\
\hline Development rate (m/day) & 7 & 7 \\
\hline $\begin{array}{l}\text { Production drilling } \\
\text { (days/stope) }\end{array}$ & 7 & 7 \\
\hline Mucking rate (t/day) & 2,000 & 2,000 \\
\hline Fill dilution $(\%)$ & $6 \%$ & $2 \%$ \\
\hline $\mathrm{Cu}$ grade $(\%)$ & $3.0 \%$ & $3.0 \%$ \\
\hline Broken metal $(\mathrm{t})$ & 1,069 & 1,069 \\
\hline Mill recovery $\%$ & $90 \%$ & $91 \%$ \\
\hline Recovered $\mathrm{Cu}(\mathrm{t})$ & 962 & 973 \\
\hline Tonnes material mined & 37,778 & 36,353 \\
\hline $\begin{array}{l}\text { Diluted recovered } \mathrm{Cu} \text { grade } \\
(\%)\end{array}$ & $2.5 \%$ & $2.7 \%$ \\
\hline Fill and cure time (days) & 126 & 48 \\
\hline Water flushed ( $\mathrm{t}$ ) & 1,800 & 200 \\
\hline
\end{tabular}

* 24 hour fill rate is an average daily filling rate - based on accounting for any required pausing in backfilling to allow for the drainage of excess water in the stope arising from backfilling

In Figure 4 the timelines for the stope cycle with backfilling by CHF and paste are illustrated. It can be seen that the filling of the previous stope (i.e. starting with Stope 1) takes 36 days and is then followed by up to 90 days of curing before a full side of the fill can be exposed by the next stope. Of course some development could begin before filling is completely cured, subject to managing risks to an acceptable level, but for this simple case this is ignored as this is relevant to either fill type placed. 
Cemented Hydraulic Backfill

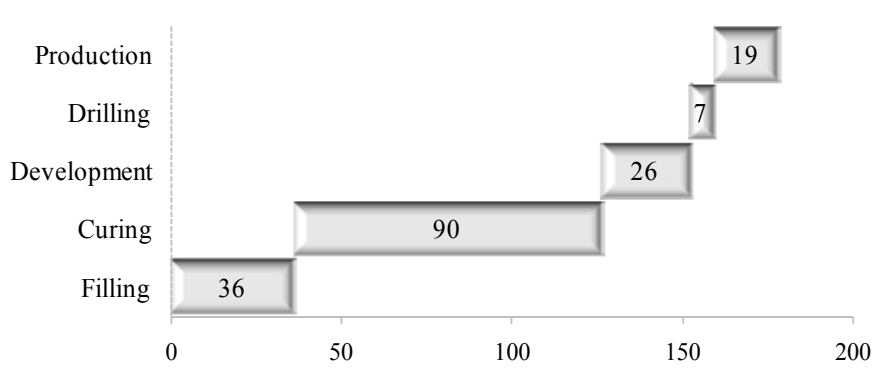

Paste Backfill

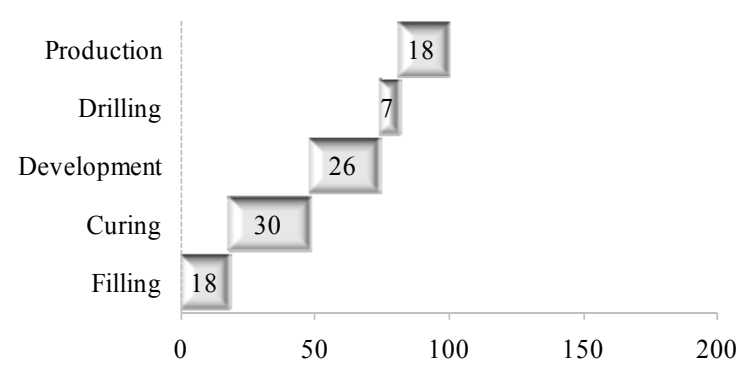

Figure 4 Major tasks and timeline schedule of a CHF and paste backfill stope lifecycle

The summary time taken for the lifecycle of a 35,000 tonne stope in this scenario is estimated at 178 days. With eight stopes in the sequence this adds up to approximately four years. It is evident that the filling related tasks account for $71 \%$ of the stope lifecycle.

If we consider a paste fill version of the same scenario in Figure 3 the overall stope activity time is reduced to 99 days with the filling tasks accounting for just $48 \%$ of the overall time. The overall time for a stope cycle is reduced by $44 \%$ by using paste backfill in this example.

If these are scaled up to mine all eight stopes the time taken to mine the orebody is reduced from four years to less than two and a half years. This affords an opportunity to increase throughput of ore from this area and the mine if other capacities are not already maximised (i.e. ore to the mill). This is presented in Figure 5.
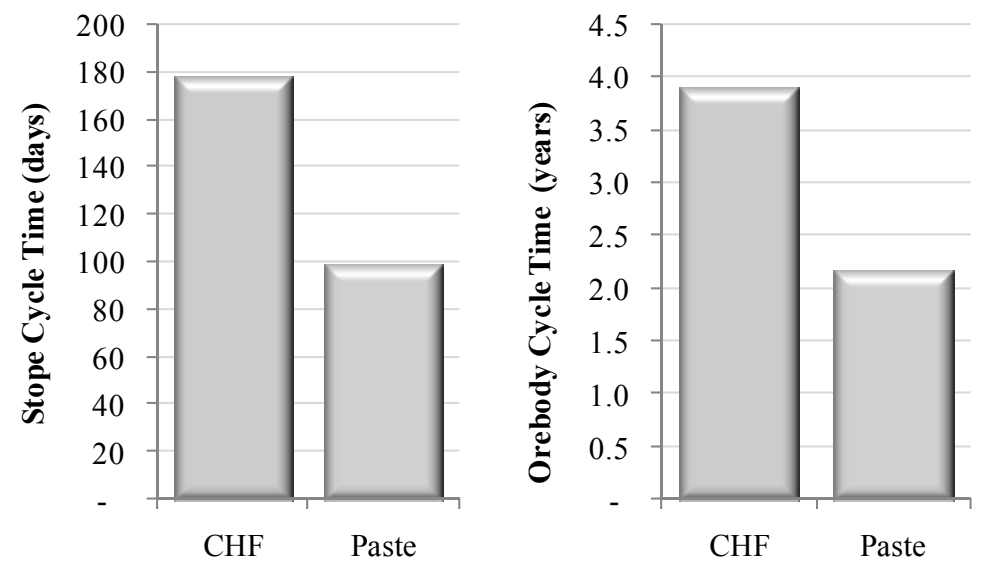

Figure 5 Stope and orebody lifecycle times

Examining a situation where the curing times are largely similar, say 30 days, for either backfill type, schedule based advantages are still achieved with the use of paste. This is because the whole stope can be filled with paste more quickly than with CHF. With CHF the backfill placement must cease for periods to permit drainage of excess water to occur before further backfill can be placed. In such a scenario a scheduling improvement for one stope can still be achieved in the order of $16 \%$ reduction in time.

\subsection{Financial}

Reviewing all the key mining requirements associated with the backfilling, costs and revenue are illustrated for many elements in Table 2. This includes for both backfill types and for one stope as well as all eight stopes in the orebody.

These are indicative costs based on real examples and presented in Australian dollars (A \$). But one should not get distracted by the costs in too much explicit detail or the currency, as the key observation is the relative difference that is calculated for the two differing backfills. 
The data reports a notional figure for revenue and profit/loss for the stope. These are indicative as many aspects of the mining process have been ignored in this simple case example. Therefore the values presented do not represent a real profit/loss for a whole of mine operation. However, the variance between the backfill types is important to note as in any mining example with a full cost model, many other factors such as refining, transportation, other mine labour and ancillary costs would on the whole remain equal for either backfill method.

Table 2 Costs and revenue (A\$)

\begin{tabular}{|c|c|c|c|}
\hline Stope Cycle Element & With CHF Backfill & With Paste Backfill & Paste Gain/(Loss) \\
\hline Backfill cost $(\$ / t)$ & 9.0 & 6.0 & $33 \%$ \\
\hline Water pumping cost $(\$ / t)$ & 0.8 & 0.8 & - \\
\hline Development cost $(\$ / m)$ & 5,000 & 5,000 & - \\
\hline Drilling cost $(\$ / m)$ & 3.3 & 3.3 & - \\
\hline Mucking cost (\$/t) & 5.0 & 5.0 & - \\
\hline Milling ore cost $(\$ / t)$ & 6.0 & 6.0 & - \\
\hline Fill cost $(\$)$ & 162,000 & 108,000 & $33 \%$ \\
\hline Water handling cost (\$) & 5,760 & 1,600 & $72 \%$ \\
\hline Development cost (\$) & 905,000 & 905,000 & - \\
\hline Drilling cost $(\$)$ & 115,830 & 115,830 & - \\
\hline Mucking cost (\$) & 188,892 & 181,764 & $4 \%$ \\
\hline Milling ore cost $(\$)$ & 226,670 & 218,117 & $4 \%$ \\
\hline Total cost (\$/stope) & $1,604,152$ & $1,530,311$ & $5 \%$ \\
\hline Price (\$/cu.t) & 6,000 & 6,000 & - \\
\hline Notional revenue (\$/stope) & $5,773,680$ & $5,837,832$ & $1 \%$ \\
\hline Notional profit (loss) (\$/stope) & $4,169,528$ & $4,307,521$ & $3 \%$ \\
\hline Notional margin (\$/cu.t) & 4,333 & 4,427 & $2 \%$ \\
\hline Total cost ( $\$ / 8$ stopes) & $12,833,219$ & $12,242,486$ & $5 \%$ \\
\hline Notional revenue ( $\$ / 8$ stopes) & $46,189,440$ & $46,702,656$ & $1 \%$ \\
\hline Notional profit (loss) (\$/8 stopes) & $33,356,221$ & $34,460,170$ & $3 \%$ \\
\hline
\end{tabular}

It is apparent that improvements are measured in areas of backfill cost, water cost, mucking cost, milling cost and a resulting slight increase in profit is achieved of approximately $3 \%$. This equates to AU\$ $1 \mathrm{M}$ over the orebody stopes.

\subsection{Value}

Taking the schedule and costs previously discussed as well as capital cost estimation for the respective backfill plants, an indicative NPV can be calculated for the case study.

In this example a CHF plant is considered to have a capital cost of AU\$10M and a paste plant of AU\$15M. Incorporating these capital expenditures over the timelines and cash flows for the full orebody mining with each backfill method, a NPV can be calculated. It is to be noted that this NPV is notional as this example only considers the capital cost of the backfill plant. All other capital costs are ignored and assumed to remain equal. 
A simple summary of the capital cost, cash flow and NPV is presented in Table 3 and 4 for the case with both backfill options.

Table 3 CHF mine life and notional NPV

\begin{tabular}{llll}
\hline Year & Capital Cost $\mathbf{( \$ M )}$ & Cash Flow (\$M) & NPV (\$M) \\
\hline 0 & $(10)$ & 0 & \\
1 & - & 4.2 & \\
2 & - & 12.5 & \\
3 & - & 8.3 & \\
4 & - & 8.3 & \\
5 & - & 0 & 2.8 \\
NPV & & & \\
\hline
\end{tabular}

Table 4 Paste mine life and notional NPV

\begin{tabular}{llll}
\hline Year & Capital Cost (\$M) & Cash Flow (\$M) & NPV (\$M) \\
\hline 0 & $(15)$ & - & \\
1 & - & 12.9 & \\
2 & - & 17.2 & \\
3 & - & 4.3 & \\
4 & - & - & \\
5 & - & - & 25.2 \\
NPV & & &
\end{tabular}

NB. All cash flows are unadjusted for inflation (not escalated) over the life of mine and the cost of capital is $10 \%$.

It is apparent that an $11 \%$ improvement in the notional NPV can be achieved with the extra expenditure and investment associated with the past backfill.

And if the same example is examined over the orebody mining with no difference in curing time of the backfills, an improvement in notional NPV is still achieved of 3\% (>AU\$0.7M) by using paste fill.

It is clear that if a mine can produce more ore in less time, increase metal recovered or provide a greater opportunity to ensure its mine schedule has contingency options to mitigate uncertainty in grade or stope performance and deliver or exceed its business plan then value is added.

Paste plants invariably amount to more in capital cost than conventional cemented hydraulic fill plants as a result of a higher level of engineering of the materials. If the capital is available to a mining operation, the overall gain to the net present value (NPV) of a business can be increased through the examples discussed.

By mining more ore or ore of higher grade in a quicker fashion than would be possible with cemented hydraulic backfill, the additional cost of a paste plant is offset by the increase in NPV.

\section{Discussion}

In both the simple scenarios described, despite a plausible paste fill plant cost to be $50 \%$ more than a cemented hydraulic fill plant to build, i.e. capital cost, the NPV could be increased in the order of 3 to $11 \%$ by enabling higher throughput rates of metal production from the mine. This range of NPV increases relate to a variety of factors, but an important one to consider is the potential for leveraging of higher gains when metal prices are high. This is created by mining and producing more metal sooner in the years ahead which intuitively provides for higher revenues. 
It can typically be shown that the larger the orebody and the greater the mining rate, the more significant the payback from operating costs savings related to reduced cement binder consumption and an even greater increase in NPV for paste. As an engineered fill, binder, water and strength are optimised for cost and performance. A typical reduction in 30 to $50 \%$ binder consumption when using paste is achieved over CHF. For an average large stoping operation, $5 \%$ binder may be reduced to $3 \%$ binder, saving $40 \%$ in cement costs, which are a major component of backfilling costs.

The consequence of an increase in production rate is of course a reduction in the life of the orebody or mine. From four years to just over two years in this example. This is often an emotive consideration for the owners of a mineral asset which is a finite resource and can influence the decisions the mine owners make. However, the business decision should be driven to reduce the life of the mine by increasing operational throughput, investing in the paste plant and delivering an improved NPV - all other factors remaining equal.

Other mining methods requiring a variation on this simple retreat sequence example will also yield a value gain. The key benefits are an increased rate of filling and a reduced curing time of filling. Both of these elements are key components of a mine schedule which if understood and planned well delivers greater throughput and reduced variability downstream to the mill, refinery and the market.

\section{Summary}

The discussions and case example presented in this paper demonstrates clearly areas of improvement that can be achieved in an underground mine by backfilling with paste rather than CHF.

The advantages include direct benefits and indirect benefits to the mining operation which create opportunities to improve key aspects such as stope cycle time, production scheduling, water consumption and rehandling, mine environment and many other factors. These all combine to counter the additional capital cost that is associated with a paste backfill plant and lend themselves to creating a higher NPV for the mining operation.

A case by case analysis is recommended for every underground mine as the scale of gains may differ depending on the nature and scale of the mining method.

\section{Acknowledgements}

The author expresses his thanks to his employer for the support in developing this paper and the opportunity to publish it at this conference.

\section{References}

Bloss, M.L., Cowling, R. and Meek, J.L. (1993) A procedure for the design of stable cemented fill exposures, in Proceedings Minefill 93, South African Institute of Mining and Metallurgy, Johannesburg, South Africa.

Li, T., Singh, U., Coxon, J., Grice, T. and Sainsbury, D. (2002) Development and application of paste fill using dry tailings, in Proceedings First International Seminar on Deep and High Stress Mining, Australian Centre for Geomechanics, Perth, Australia, Section 12.

Runge, I. (1998) Mining economics and strategy, Society for Mining, Metallurgy and Exploration Incorporated, United States.

Slade, N.M., Felipe, F., Wilson, S. and Palkovits, F. (2009) Increasing Value in Mining Operations through the Application of Paste, in Proceedings 13th AusIMM Mill Operators Conference, Australian Institute for Mining and Metallurgy, Adelaide, Australia.

Slade, N.M., Guilfoyle, K. and Kropp, W. (2006) Strategic and tactical mine planning in Enterprise Mine, Mount Isa Copper Operations, in Proceedings Strategic versus Tactical Approaches in Mining, Australian Centre for Geomechanics, Perth, Australia, Section 39. 
